\title{
Diurnal, land-based predation on shore crabs by moray eels in the Chagos Archipelago
}

Received: 27 November 2008/ Accepted: 17 February 2009/Published online: 8 March 2009

(C) Springer-Verlag 2009
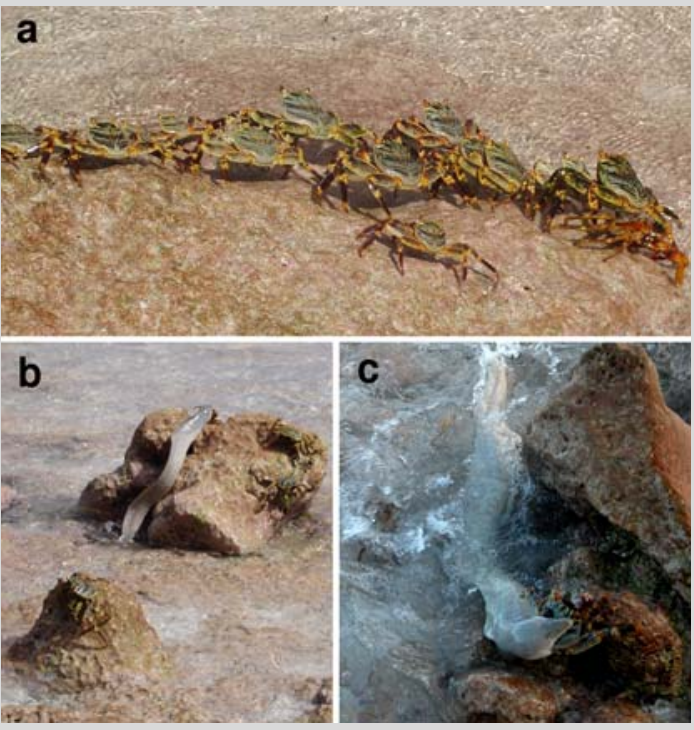

Fig. 1 Shore crabs, Grapsus tenicrustatus, forage along the waterline (a). Peppered moray eels, Gymnothorax pictus, actively hunt and leap clear of the water to capture their prey $(\mathbf{b}, \mathbf{c})$ Chagos Archipelago, may provide interesting insights into the natural dynamics of many species whose abundance and behaviour have been altered due to human activity elsewhere.

Acknowledgements The Chagos Research Expedition of 2006, funded largely by the FCO, London, and organised by Charles Sheppard enabled this work to take place. Additional funding came from the Leverhulme Trust and the Fisheries Society of the British Isles.

\section{Reference}

Lieske E, Myers R (1994) Coral reef fishes, Indo-Pacific and Caribbean including the Red Sea. Harper Collins Publishers, London

N. A. J. Graham ( $\bowtie)$

ARC Centre of Excellence for Coral Reef Studies, James Cook University, Townsville, QLD 4812, Australia e-mail: Nick.Graham@jcu.edu.au

\section{S. J. Purkis}

National Coral Reef Institute, Nova Southeastern University, Oceanographic Centre, 8000 N. Ocean Drive, Dania Beach, FL 33004, USA

A. Harris

Department of Biological Sciences, University of Warwick, Coventry, CV4 7AL, UK

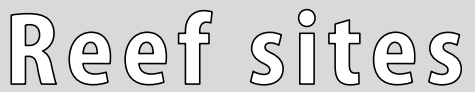

Coral Reefs (2009) 28:397

DOI $10.1007 / \mathrm{s} 00338-009-0488-6$ 